Tropical Journal of Pharmaceutical Research September 2014; 13 (9): 1537-1543

ISSN: $1596-5996$ (print); 1596-9827 (electronic)

(c) Pharmacotherapy Group, Faculty of Pharmacy, University of Benin, Benin City, 300001 Nigeria.

All rights reserved.

Available online at http://www.tjpr.org

Original Research Article

http://dx.doi.org/10.4314/tjpr.v13i9.22

\title{
A Pilot Study Assessing the Barriers to Pharmacy Practice in Dubai, United Arab Emirates
}

\author{
Ibrahim Khalid Rayes ${ }^{1 *}$, Mohamed Azmi Hassali ${ }^{1}$ and Abduelmula R \\ Abduelkarem² \\ ${ }^{1}$ Discipline of Social and Administrative Pharmacy, School of Pharmaceutical Sciences, Universiti Sains Malaysia, 11800 \\ Minden, Penang, Malaysia, ${ }^{2}$ Department of Pharmacy Practice and Pharmaco-therapeutics, College of Pharmacy, University of \\ Sharjah, PO Box 27272, Sharjah, United Arab Emirates
}

*For correspondence: Email: rayes_mb@eim.ae; Tel: +971 50 5758354; Fax: + 97143368886

Received: 31 December 2013

Revised accepted: 23 July 2014

\begin{abstract}
Purpose: To explore the barriers to the practice of pharmacy in Dubai, United Arab Emirates (UAE). Methods: In a questionnaire-based cross-sectional study, 50 questionnaires were distributed to randomly selected pharmacies in Dubai. The questionnaire contained information for collecting data on demographic data, technical-related information, and barriers to optimized pharmaceutical services.

Results: $A$ total of 31 of the 50 questionnaires were returned, giving a response rate of 62 percent. Of these, 20 (65\%) were male, 25 (81 \%) holding bachelor degree, and almost three quarters 23 (74\%) were Indian and had their bachelor degree in India. More than half $(n=18,59 \%)$ reported that they functioned as pharmacists-in-charge and dispense more than 100 prescriptions in 1 business week during the study period. Enhanced pharmacy services offered by pharmacists under investigation were minimal for drug outcomes monitoring (9.68\%), counseling in hyperlipidaemia (6.45\%), and hypertension (9.68 \%). A high proportion of pharmacists studied agreed that pharmacists lack customers' recognition in Dubai (54.8\%) and receive inadequate salary (67.8\%), and that pharmacy practice in Dubai is business-oriented (74.2\%). Nearly all the pharmacists $(93.5 \%)$ agreed that lack of sales bonus and high running costs are major barriers to optimized pharmacy services in Dubai.

Conclusion: This pilot study gives some insight into the impediments community pharmacists in Dubai face while delivering pharmacy services to patients. These findings can be used to promote discussion in the profession and with stakeholders about the future role of the community pharmacist in patient care in UAE.
\end{abstract}

Keywords: Barriers; Community pharmacy; Pharmacy practice; United Arab Emirates, Drug outcomes monitoring, Counseling

Tropical Journal of Pharmaceutical Research is indexed by Science Citation Index (SciSearch), Scopus, International Pharmaceutical Abstract, Chemical Abstracts, Embase, Index Copernicus, EBSCO, African Index Medicus, JournalSeek, Journal Citation Reports/Science Edition, Directory of Open Access Journals (DOAJ), African Journal Online, Bioline International, Open-J-Gate and Pharmacy Abstracts

\section{INTRODUCTION}

Over the last two decades pharmacists' role has transformed from product orientation services to patient centered services in many parts of the world [1-3]. Within the context of change, there has been a need for the pharmacist to interact with different categories of patients, health service providers, and governmental officials who assisted in opening wider healthcare delivery opportunities for pharmacists. However, there are many barriers which restrict the efficient delivery of pharmaceutical services in a community pharmacy.

Community pharmacists have an important role of healthcare delivery because of their location 
within communities which made them close to patients and even they are often the first respondents in healthcare system [4]. To ensure that delivery of pharmacy services is optimized, there should be proper training for pharmacists and enough supply of manpower. In fact, the number of registered pharmacists in UAE remains lower than the accepted worldwide number of pharmacists in a population. The proportion of pharmacists to 10,000 citizens in the UAE was about 4 in 2002 [5]. There are nearly 2000 private pharmaceutical organizations across the UAE which are staffed by pharmacists and assistant pharmacists from over 20 countries $[6,7]$. Yet, the number of pharmacies is rapidly growing in the country due to higher demand of healthcare services caused by fast population growth from both UAE nationals and expatriates in addition to the development of many new civilized towns and cities which required availability of advanced healthcare services. Newer statistics stated that the number of newly registered pharmacists was about 300 every year between the years 2005 till 2010 [7].

UAE is one of the rich Gulf Cooperation Council countries in the Middle East and has a gross domestic product (GDP) per capita of around US\$52,435 [8,9]. It has a diverse and rapidly expanding population which was estimated to break the mark of 8 million in 2010 [10]. However, UAE nationals are considerably few compared to expatriates (other Arab countries, Iran, South East and South Asia) who constitute approximately $88.5 \%$ of the total population [10]. Demand for healthcare services is continuously expanding in the country due to the dramatic influx of expatriates. In general, the current characteristics of services provided in community pharmacies within the Arab countries are rarely documented in the literature $[11,12]$. It has been reported in one particular study [13] that there are many limitations in services provided and shortages in product availability. More recently, the pharmacy practice situation and the barriers to optimizing pharmacy services delivery in UAE are not fully known, as well as factors that negatively affect their ability to provide services in pharmacies [14-17]. Such information is needed prior to formulation of plans by the Ministry of Health $(\mathrm{MOH})$ to enhance pharmacy practice delivery systems within UAE.

The objective of this study was to investigate the barriers to optimizing the delivery of pharmaceutical services in UAE, as well as suggest ways to overcome these obstacles.

\section{EXPERIMENTAL}

There are almost 600 community pharmacies operating within the emirate of Dubai [18]. In this pilot study, 50 questionnaires were personally distributed to 50 randomly selected community pharmacies in Dubai Health Authority area. The pharmacists in charge of the pharmacies who agreed to participate were given 2 choices; either to answer the questionnaire and handle it on the spot or handle it later on. Pharmacists who chose the second option were visited 1 week later to collect the completed questionnaires.

The questionnaire was developed specifically for this work based on previous similar studies [19, 20]. It had sections to collect information on social demographic data (including age, gender, and nationality), date of obtaining $\mathrm{MOH}$ license, practical issues related to daily pharmacy practice (including questions about the pharmacist's qualification, location of obtaining the qualification, position in the pharmacy, number of prescriptions dispensed in one week, and number of non-prescription products initiated in pharmacy, references usage frequency, availability and usage of dispensary computer, and ways used to contact physicians) as well as information related to pharmacists' perception on main barriers to offer high quality pharmaceutical services. For most questions, the respondents were asked to rate their response using the options "strongly disagree", "disagree", "unsure", "agree" and "strongly agree". There are many examples in the literature to support the use of a five-choice scale. The questionnaire was pretested and modified as appropriate before use.

This study was approved by Universiti Sains Malaysia Ethics Committee in Malaysia and Ajman University of Science and Technology Human Research Ethics Committee in the UAE. The study was carried out over a period of three months (October 01, 2012 to December 31, 2012).

\section{Data analysis}

The Statistical Package for the Social Sciences (SPSS), version 20.0, was used to enter and analyze the data (such that $95 \%$ confidence intervals could be calculated for Strongly agree or agree responses). When analyzing the data the responses from the five-point scale were reduced to three categories: strongly disagree/disagree, unsure, and agree/strongly agree. This enabled more reader comprehensible confidence intervals for the relative proportions to be calculated. Descriptive analysis was used to calculate the proportion of 
each group of respondents who agreed/disagreed with each statement regarding the barriers to pharmacy services item. In addition, relative proportions were calculated for categorical variables when it is possible.

\section{RESULTS}

A total of 31 of the 50 questionnaires were returned, giving a response rate of $62 \%$. Of these, 20 (64.5\%) were male, 25 (80.6\%) holding bachelor degree, and almost three quarters $23(74.2 \%)$ were Indian and had their bachelor's degree in India. More than half 16 $(51.6 \%)$ of them were less than 41 years old and only $6(19.4 \%)$ were in the age bracket of 51 61 years or more (Table 1 ).

The pharmacist in charge was employed on a full time basis in more than half 18 (58.1\%) pharmacies included in the study. More than half $18(58.1 \%)$ reported that they were dispensing more than 100 prescriptions in 1 business week during the study period. However, the average time spent with a patient was less than five minutes by almost half $14(45.2 \%)$ and between five to ten minutes by $17(54.8 \%)$ of them. None of the pharmacists included in the study reported that they spent more than ten minutes with their patients during the pharmacist-patient encounters. Most of the pharmacists under investigation reported that they initiated medications and other health related products by their own without prescriptions in their pharmacies such as vitamins (29; $93.5 \%$, nonsteroidal anti-inflammatory drugs (NSAIDs) (27; $87.1 \%)$, tooth pastes (28; $90.3 \%)$, cough remedies (30; $96.8 \%)$, anti-allergies (27; 87.1 $\%)$, nasal decongestants $(27 ; 87.1 \%)$, and eye drops $(24 ; 77.4 \%)$. In addition, enhanced pharmacy services are mostly limited to providing diet plans 16 (51.6\%), herbal medicines 17 (54.8 $\%)$, nutritional supplements 21 (67.7 \%), skin care 22 (71\%), smoking cessation 17 (54.8\%), and weight reduction 16 (51.6\%) (Table 2).

Although access to the Internet was available in the pharmacies where the pharmacists worked, only $17(54.8 \%)$ of the respondents made frequent use of it and almost half 15 (48.4\%) reported that they do not have computer in their pharmacies. The British National Formulary (BNF) was the main $25(80.6 \%)$ reference book. However, Web-based information was commonly used by $19(61.3 \%)$ of the pharmacists during the study period. The CD ROM's such as MIMS and Martindale were only used by $3(9.7 \%)$ and $4(12.9 \%)$ respectively. Table 3 illustrates the types of references used by pharmacists in their daily practice during the study period.

Table 1: Pharmacists' demographic information (Gender, age, nationality, country and highest qualification)

\begin{tabular}{|c|c|}
\hline Pharmacist & $\mathbf{N}(\%)$ \\
\hline \multicolumn{2}{|l|}{ Gender } \\
\hline Male & $20(64.5)$ \\
\hline Female & $11(35.5)$ \\
\hline \multicolumn{2}{|l|}{ Age (years) } \\
\hline $21-30$ & $3(9.7)$ \\
\hline $31-40$ & $13(41.9)$ \\
\hline $41-50$ & $9(29)$ \\
\hline $51-60$ & $5(16.1)$ \\
\hline $61+$ & $1(3.2)$ \\
\hline \multicolumn{2}{|l|}{ Nationality } \\
\hline Indian & $23(74.2)$ \\
\hline Pakistani & $3(9.7)$ \\
\hline Egyptian & $2(6.5)$ \\
\hline Syrian & $3(9.7)$ \\
\hline \multicolumn{2}{|c|}{ Country of qualification } \\
\hline India & $23(74.2)$ \\
\hline UAE & $1(3.2)$ \\
\hline Syria & $1(3.2)$ \\
\hline Pakistan & $3(9.7)$ \\
\hline Turkey & $1(3.2)$ \\
\hline Egypt & $2(6.5)$ \\
\hline \multicolumn{2}{|l|}{ Highest Qualification } \\
\hline Diploma & $3(9.7)$ \\
\hline B Pharm & $25(80.6)$ \\
\hline M Pharm & $1(3.2)$ \\
\hline Pharm D & $2(6.5)$ \\
\hline \multicolumn{2}{|l|}{ Position held } \\
\hline Sole proprietor & $4(12.9)$ \\
\hline Partner proprietor & $1(3.2)$ \\
\hline Salaried manager & $1(3.2)$ \\
\hline Pharmacist in-charge & $18(58.1)$ \\
\hline Second pharmacist & $7(22.6)$ \\
\hline
\end{tabular}

Almost half 15 (48.4\%) of the respondents either strongly disagreed or disagreed that time was a major barrier to effective service delivery, while $23(74.2 \%)$ and more than half 17 (54.8\%) of the respondents believed that pharmacy practice turned to be a business and lack of customers' recognition, respectively. In addition, almost all respondents $(93.5 \%)$ agreed that high running expenses and lack of sales bonuses are barriers 
Table 2: Drug dispensing, pharmacy prescribing and Enhanced pharmacy services offered in Dubai community pharmacies

\begin{tabular}{|c|c|}
\hline Variable & $\mathbf{N}(\%)$ \\
\hline \multicolumn{2}{|l|}{$\begin{array}{l}\text { Number of prescriptions } \\
\text { dispensed in one week }\end{array}$} \\
\hline 0 to 10 & $1(3.2)$ \\
\hline 10 to 50 & $6(19.4)$ \\
\hline 50 to 100 & $6(19.4)$ \\
\hline $100+$ & $18(58.1)$ \\
\hline \multicolumn{2}{|l|}{$\begin{array}{l}\text { Medicines prescribed } \\
\text { in pharmacy }\end{array}$} \\
\hline Vitamins & $29(93.5)$ \\
\hline NSAIDs & $27(87.1)$ \\
\hline Antibiotics & $12(38.7)$ \\
\hline Nicotine repl. Therapy & $16(51.6)$ \\
\hline Tooth paste & $28(90.3)$ \\
\hline Blood press. Agents & $4(12.9)$ \\
\hline Cough remedies & $30(96.8)$ \\
\hline Anti-allergies & $27(87.1)$ \\
\hline Nasal decongestants & $27(87.1)$ \\
\hline Eye drops & $24(77.4)$ \\
\hline Oral hypoglycemic & $4(12.9)$ \\
\hline Cholesterol lowering & $3(9.7)$ \\
\hline \multicolumn{2}{|l|}{$\begin{array}{l}\text { Enhanced pharmacy } \\
\text { services offered }\end{array}$} \\
\hline Diet plans & $16(51.6)$ \\
\hline Drug level monitoring & $3(9.7)$ \\
\hline Herbal medicines & $17(54.8)$ \\
\hline Hyperlipidaemia & $2(6.5)$ \\
\hline Hypertension & $3(9.7)$ \\
\hline Nutritional suppl. & $21(67.7)$ \\
\hline Osteoporosis & $4(12.9)$ \\
\hline Paediatric care & $6(19.4)$ \\
\hline Skin care & $22(71)$ \\
\hline Smoking cessation & $17(54.8)$ \\
\hline Weight reduction & $16(51.6)$ \\
\hline Wound care & $17(54.8)$ \\
\hline Other & $1(3.2)$ \\
\hline
\end{tabular}

to service delivery Furthermore, high proportion $21(67.7 \%)$ of pharmacists agreed that inadequate wages for pharmacists, hinder service delivery. Other factors identified to be barriers to service delivery included underestimation by other healthcare professional $(68.7 \%)$, and lack of interpersonal and management skills by pharmacists $(58.1 \%)$. Interestingly, more than half $18(58.1 \%)$ of the respondents had confidence in their skills of handling patients (Table 4).

Table 3: Reference books and computer usage in daily pharmacy practice

\begin{tabular}{lc}
\hline Variable & N (\%) \\
\hline $\begin{array}{l}\text { References used in } \\
\text { pharmacies }\end{array}$ & \\
BNF & $25(80.7)$ \\
CD ROM's (e.g. MIMS) & $3(9.7)$ \\
Martindale & $4(12.9)$ \\
MIMS or other guides & $16(51.6)$ \\
Pharm. data base & $2(6.5)$ \\
Web-based info. & $19(61.3)$ \\
Other & $3(9.7)$ \\
\hline Dispensing computer & \\
usage & $15(48.4)$ \\
Not available & $21(67.7)$ \\
Barcode reader & $17(54.8)$ \\
Regular internet use & $18(58.1)$ \\
Regular e-mail use & $1(3.2)$ \\
\hline
\end{tabular}

\section{DISCUSSION}

The key findings of this study highlight some of the obstacles that hinder optimum delivery of pharmaceutical care in community pharmacies in Dubai.

A total of $25(80.6 \%)$ pharmacists in this study were bachelor degree holders coming from India (23; $74.2 \%)$ followed by Pakistan, Syria, and Egypt. This study lacked the availability of UAE national pharmacists as their number is considerably low [10]. Most of the screened pharmacists $(26 ; 83.9 \%)$ were only employees as most of pharmacies' owners were nonpharmacists [21]. This might be the reason why some pharmacists were feeling high pressure to generate sales $20(64.5 \%)$ by their employers and it can be part of what's felt to be a shift of the profession into business orientations 23 (74.2 $\%)$. This is not the only obstacle which was causing hindrance to optimized pharmacy services. More than half of respondents 17 (54.8 $\%)$ felt that they are under-estimated by customers while $21(67.7 \%)$ reported lack of recognition by other healthcare professionals. On the other side, pharmacists disagreed with the statement "there is a lack of knowledge by pharmacists in Dubai" 18 (58.3 \%) and they argued that they have the required confidence 23 $(74.2 \%)$ and interpersonal skills $18(58.1 \%)$. 
Table 4: Barriers to pharmacy service delivery

\begin{tabular}{|c|c|c|c|c|}
\hline Barriers to pharmacy services & $\begin{array}{l}\text { Strongly } \\
\text { disagree/dis } \\
\text { agree }\end{array}$ & Unsure & $\begin{array}{l}\text { Strongly } \\
\text { agree/ } \\
\text { agree }\end{array}$ & $\begin{array}{l}(95 \% \mathrm{Cl}) \text { for } \\
\text { Strongly agree } \\
\text { or agree } \\
\text { responses }\end{array}$ \\
\hline & $\mathrm{n}(\%)$ & $\mathrm{n}(\%)$ & $\mathrm{n}(\%)$ & $(\%)$ \\
\hline Shortage of time to offer services & $15(48.4)$ & $4(12.9)$ & $12(38.7)$ & $21.65-55.77$ \\
\hline Shortage of pharmacists and/or employees & $14(45.2)$ & $1(3.2)$ & $16(51.6)$ & $34.11-69.12$ \\
\hline Lack of customers' demand and recognition & $12(38.7)$ & $2(6.5)$ & $17(54.8)$ & $37.41-72.27$ \\
\hline Lack of appropriate knowledge by pharmacists & $18(58.1)$ & $6(19.4)$ & 7 (22.6) & 7.94-37.22 \\
\hline \multirow{2}{*}{$\begin{array}{l}\text { Lack of confidence by pharmacy staff } \\
\text { It is not felt by pharmacists to be part of their job }\end{array}$} & $23(74.2)$ & $2(6.5)$ & $6(19.4)$ & $5.52-33.19$ \\
\hline & $20(64.5)$ & $1(3.2)$ & $10(32.3)$ & $15.89-48.63$ \\
\hline \multirow{2}{*}{ Lack of rights and protection against malpractice } & $9(29)$ & $1(3.2)$ & $21(67.7)$ & $51.37-84.1$ \\
\hline & $9(29)$ & $4(12.9)$ & $18(58.1)$ & $40.78-75.35$ \\
\hline \multirow{2}{*}{$\begin{array}{l}\text { Under-estimation by other healthcare } \\
\text { professionals } \\
\text { High pressure on pharmacists to generate sales }\end{array}$} & $3(9.7)$ & $7(22.6)$ & $21(67.7)$ & $51.37-84.11$ \\
\hline & $6(19.4)$ & $5(16.1)$ & $20(64.5)$ & $47.76-81.27$ \\
\hline \multirow[t]{2}{*}{$\begin{array}{l}\text { Lack of financial rewards from enhanced } \\
\text { pharmacy services } \\
\text { Inefficient Pharmacy training before graduation }\end{array}$} & $6(19.4)$ & $5(16.1)$ & $20(64.5)$ & $47.76-81.27$ \\
\hline & $11(35.5)$ & $6(19.4)$ & $14(45.2)$ & $27.73-62.59$ \\
\hline \multirow[t]{2}{*}{$\begin{array}{l}\text { Lack of interpersonal and management skills by } \\
\text { pharmacists } \\
\text { Pharmacy practice turned to be a business }\end{array}$} & $18(58.1)$ & 5 (16.1) & $8(25.8)$ & $10.48-41.13$ \\
\hline & $5(16.1)$ & $3(9.7)$ & $23(74.2)$ & 58.87-89.52 \\
\hline $\begin{array}{l}\text { High running cost expenses in addition to sales } \\
\text { bonus stoppage }\end{array}$ & $0(0)$ & $2(6.5)$ & $29(93.5)$ & $84.94-100.00$ \\
\hline
\end{tabular}

These results were consistent with more than one study about constraints to enhanced pharmaceutical services [14,16]. About half 17 (55\%) of the respondents claimed that they spend an average of 5-10 min with every customer. This can be justified by a fact that there is an indulging requirement from medical insurance organizations to get phone and/or online approvals for most of prescription claim forms which usually take significant amount of time. These findings are consistent with a study on the general public in Canada by Jason who stated that the public possess positive perceptions towards community pharmacists' profession, but there is still some variation, perhaps showing that an inconsistent message is being communicated to the general public about the role of pharmacists [22].

From the above points; pharmacy practice in Dubai is pushing for fast development. Nevertheless, it has its own restriction factors which might be internal as lack of time to offer services $12(38.7 \%)$ and shortage of pharmacists 16 (51.6\%). Other factors could be external like "lack of rights and pharmacist's protection against malpractice" 18 (58.1\%) and high running cost in addition to sales bonus stoppage 29 (93.5\%).

\section{Limitations of the study}

Due to the necessity of distributing questionnaires via personal visits to the pharmacy and the reluctance of many pharmacists to participate in a survey, the target sample for this pilot study was only nearly reached; probably more questionnaires could have been covered during the study period. Recognizing the limitation of convenient sampling methods, the resulting sample may not be representative of the population from which it is drawn; however, since it was a pilot study and a clear criterion was used in sampling, we can argue that the data we managed to collect do not reflect the views of the pharmacists. The low number of pharmacists involved with only 31 questionnaires fully completed by the responding pharmacists may introduce a bias. However, this study was carried out over a large demographic area of Dubai and many negative opinions were expressed. Therefore, one may argue that such an assumption is not supported by the results. However, in order to avoid any hint of selection 
bias and to make findings more generalized, more pharmacists from other regions should be involved in future studies which will be based on this pilot study finding. Additionally, it would seem prudent to follow up non-responders in order to achieve a higher response rate.

The study was not based on hospital pharmacists, whose opinion and practices may vary. Although, the results cannot be generalized to other areas in the UAE or the Gulf, as it included pharmacists from only one state, the findings in this study can be valuable to any pharmacist who finds their practice setting, policies and regulations similar to UAE and has an interest in expanded pharmacist roles. Although a questionnaire was modified from a previous similar study, the test/re-test reliability has yet to be checked in the UAE. It is high time an appropriate questionnaire that takes into consideration Middle East attitudes and culture is developed for studies such as this. In addition, the differences related to whether the health care system is private or public and those related to availability of facilities should also be considered in future studies.

\section{CONCLUSION}

This paper, as a pilot study, provides an insight into some challenges that pharmacy professionals face in Dubai, UAE. The findings can be used to promote discussion in the profession and with stakeholders about the future role of the community pharmacist in patient care in the UAE. Future studies should focus on providing further data on barriers to pharmacy practice as well as exploring the perceptions of other healthcare professionals and customers on the role of community pharmacists in the country.

\section{REFERENCES}

1. Anderson S. Making medicines: a brief history of pharmacy and pharmaceuticals. Pharmaceutical Press: London, UK; 2005.

2. Andrew M. Managing pharmacy practice: principles, strategies, and systems. CRC Press: Florida, USA, 2004; 1-3.

3. Anne N, Chantal L, Olivier B. Medication reviews led by community pharmacists in Switzerland: a qualitative survey to evaluate barriers and facilitators. Pharm Pract 2010; 8(1): 35-42.

4. Smith F. Private local pharmacies in low-and-middle income countries: a review of interventions to enhance their role in public health. Trop Med Int Health 2009; 14: 362-372.
5. World Health Organization 2002. Core Health Indicators - United Arab Emirates. [Cited 2012 Dec 8]. Available from:

http://www.who.int/whosis/database/core/core_select _process.cfm?country=are\&indicators=healthpersonn el.

6. Ministry of Health - UAE 2003. Guidelines and Minimum Standards for Good Pharmacy Practice in UAE Pharmacies. [Cited 2012 Nov 30]. Available from: http://www.cpd-

pharma.ae/index.php?option=com_phocadownload\& view=category\&download=76: ministry-of-healthguideline-and-minimum-standards-for-goodpharmacy-practice-gpp-version-1-2003\&id=2: $m o h$ policies-and-circulars\&ltemid $=78$.

7. Ministry of Health - UAE 2011. Drug Registration and Control Administration Statistics 2010-2011.

8. Wikipedia. United Arab Emirates. [Cited 2012 Nov 30]. Available from: http://en.wikipedia.org/wiki/United_Arab_Emirates.

9. United Nations Development Program 2011. International Human Development Indicators, Country Profile: UAE. [Cited 2012 Nov 29]. Available from: http://hdrstats.undp.org/en/countries/profiles/ARE.htm I.

10. National Bureau of Statistics - United Arab Emirates 2010. Population Estimates 2006-2010. [Cited 2012 Nov 30]. Available from: http://www.uaestatistics.gov.ae/ReportDetailsEnglish/ tabid/121/Default.aspx? Itemld=1914\&PTID=104\&Me nuld $=1$.

11. Matowe L, Al-Kandery AS, Bihzad SM. Pharmacy in Kuwait. Am J Health Syst Pharm 2003; 60: 15911592.

12. Awad A, Abahussain E. Health promotion and education activities in community pharmacists in Kuwait. Pharm World Sci 2010; 32: 146-153.

13. Awad A, Al-Ebrahim S, Abahussain E. Pharmaceutical care services in hospitals of Kuwait. J Pharm Pharm Sci 2006; 9(2): 149-157.

14. Sanah H, Hana S, Colin C, Kay S, David K. Community pharmacy in the United Arab Emirates: characteristics and workforce issues. Intl J Pharm Prac 2011; 19: 392-399.

15. Sanah H, Hana S, Kay S, Colin C, Mohammed H, David K. Assessing patient satisfaction with community pharmacy in the UAE using a newly-validated tool. Res Soc Admin Pharm 2012; 1-10.

16. Sanah H, Hana S, Colin C, Kay S, David K. Community pharmacy services in the United Arab Emirates. Intl J Pharm Prac 2012; 20: 218-225.

17. Majd D. Pharmacy in the United Arab Emirates. South Med Rev 2009; 2(1): 15.

18. Database Web Survey Software for Gathering Information. Sample Size Calculator. [Cited 2012 Dec 31]. Available from: http://www.raosoft.com/ samplesize.html 
19. Berbatis CG. Australia's Community Pharmacy Survey: National Pharmacy Database Project, 2002-2003. National Statistical Service, Australia, 2003. [Cited 2012 Dec 15]. Available from http://www.nss.gov.au/nss/home.NSF/84c014dd96dd f6cbca257118001dbbee/d66c47a90eebd9d3ca256b2 80010f14f?OpenDocument .

20. International Pharmaceutical Federation. Standards for Quality of Pharmacy Services: Good Pharmacy Practice. FIP Congress, Istanbul, Turkey, 1997. [Cited 2012 Dec 15]. Available from:
http://www.fip.org/files/fip/Statements/latest/Dossier\% 20004\%20total.PDF.

21. Ministry Of Economy. Commercial Companies Law number 8 of 1984. [Cited 2012 Dec 31]. Available from: http://www.abudhabi.ae/egovPool Portal_WAR/appmanager/ADeGP/Citizen?_nfpb=true \&_pageLabel=p_citizen_departments\&did=21402\&la $n g=e n$.

22. Jason P. Public opinion on pharmacists and pharmacist prescribing. Can Pharm J 2011; 144(2): 86-93. 